\title{
ENTRE ENCONTROS E COMPOSIÇÕES EM MATILHA: MOVIMENTOS DE RESISTÊNCIAS E INVENÇÕES CURRICULARES
}

\section{BETWEEN MATCH MEETINGS AND COMPOSITIONS: RESISTANCE MOVEMENTS AND CURRICULAR INVENTIONS}

Hociene Nobre Pereira Werneck ${ }^{1}$

\begin{abstract}
Resumo: Este texto trata de uma pesquisa que tem como foco a potência da coletividade e se justifica pela necessidade de superação do individualismo nos trabalhos e nas relações interpessoais. Objetiva, portanto, cartografar os afetos que emergem dos encontros estabelecidos no cotidiano escolar, considerando que por meio desses encontros, de onde se deriva uma multiplicidade de composições, expande-se a potência coletiva e uma docência inventiva vai se delineando, criando novos movimentos curriculares. Dialoga com Deleuze e Guattari, Spinoza, Carvalho, dentre outros como intercessores teóricos e apresenta como abordagem metodológica a cartografia e as redes de conversações derivadas de encontros com professores e crianças de uma escola de Educação Infantil do município de Serra-ES. Acreditase que, por meio de "bons" encontros, os protagonistas do processo educativo ao se colocarem abertos às relações potencializam a constituição do "comum", fortalecendo o trabalho coletivo e os movimentos inventivos curriculares.
\end{abstract}

Palavras-chave: Coletividade; resistências; invenções curriculares.

\begin{abstract}
This text deals with research that focuses on the power of the community and is justified by the need to overcome individualism in work and in interpersonal relationships. Therefore, it aims to map the affections that emerge from the meetings established in the school routine, considering that through these meetings, from which a multiplicity of compositions are derived, the collective power expands and an inventive teaching is outlined, creating new curricular movements. Dialogues with Deleuze and Guattari, Spinoza, Carvalho, among others as theoretical intercessors and presents as a methodological approach the cartography and the networks of conversations derived from meetings with teachers and children from an early childhood school in the city of Serra-ES. It is believed that, by means of "good" meetings, the protagonists of the educational process, by being open to relations, enhance the constitution of the "common", strengthening collective work and curricular inventive movements.
\end{abstract}

Keywords: Collectivity; resistances; curricular inventions.

Quando a neve cai e os ventos brancos sopram, o lobo solitário morre, mas a matilha sobrevive!

Game of Thrones

Sobreviver! Ouve-se o uivar de professores e crianças diante da "neve" e dos "ventos brancos" que se despontam como engessamento de currículos e modelização de atitudes, limitando o trabalho coletivo no cotidiano escolar. Como enfrentá-los? Como superar o individualismo nos trabalhos e nas relações interpessoais? De que modo os professores/as fortalecem os seus vínculos em busca de compor um corpo coletivo?

\footnotetext{
${ }^{1}$ Mestranda do Programa de Pós-graduação de Mestrado Profissional em Educação- PPGMPE/UFES. E-mail: hociene@gmail.com.
} 
A nossa aposta? Produzir encontros em matilha (DELEUZE; GUATTARI, 2011). Matilha que cria resistências, que uiva em busca de outras composições e se mobiliza criando outros/novos movimentos curriculares. Sobre a força da matilha, Deleuze e Guattari (2012) já nos indicavam, ela é capaz de minar as grandes potências molares, de tumultuar os projetos significantes, de provocar uma irresistível desterritorialização.

Portanto, o presente texto trata de uma pesquisa que problematiza os encontros de formação continuada de professores, os movimentos de invenções curriculares e o trabalho coletivo que se constitui no cotidiano escolar. Busca compreender de que modo os encontros e composições estabelecidos no cotidiano escolar podem potencializar a constituição do comum, fortalecendo o trabalho coletivo e as invenções curriculares.

Nessa caçada em matilha, o nosso principal objetivo é cartografar os afetos ${ }^{2}$ que emergem dos encontros estabelecidos no cotidiano escolar, considerando que por meio desses encontros, de onde se deriva uma multiplicidade de composições, expande-se a potência coletiva e se delineia uma docência inventiva criadora de novos movimentos curriculares.

Para tanto, utilizamos como abordagem metodológica a cartografia e as redes de conversações derivadas de encontros com professores e crianças de uma escola de Educação Infantil do município de Serra-ES, cujas falas aparecerão no decorrer do texto de maneira coengendrada com os pensamentos apresentados, expressando o uivar de um coletivomatilha em sua luta por sobrevivência no cotidiano escolar.

Os atravessamentos vividos em nossas trajetórias de professoras e pedagogas na educação infantil por meio do trabalho coletivo nos fizeram enxergar a força de uma matilha que, embora pequeno em quantidade, foi capaz de resistir à fixidez de muitas normas que intencionavam limitar o movimento de crianças e professores em sua busca por mais vida nos currículos. Situações que nos fazem defender o devir-lobo de professoras ${ }^{3}$ e crianças como possibilidade de resistência em relação à domesticação das normas, das padronizações curriculares, da modelização de atitudes, do individualismo exacerbado, enfim, de tudo que aprisiona a vida.

Resistência que, conforme nos esclarece Carvalho (FERRAÇO; CARVALHO, 2008, apud, 2009, p. 4) não se trata apenas de oposição "mas, sobretudo, desconstrução, transgressão, burla e táticas produzidas nas redes cotidianas, em relação ao que está posto como norma, como determinação, como modelo" e nos faz (re)existir no cotidiano escolar, operando o nosso devirlobo numa composição de forças que faz fugir as linhas segmentares em busca de outros sentidos para o currículo.

Já de início manifestamos a nossa fascinação exercida pelos lobos, o apelo por devir-lobo. Devir-lobo das professoras, devir-lobo das crianças... Devir. Forças de resistências do coletivo escolar com seus modos próprios de matilha, pois "quem ignora efetivamente que os lobos andam em matilha?” (DELEUZE; GUATTARI, 2011, p. 54). Não podemos confundir o devir com imitação, com semelhança ou comparação. O devir não é fantasia ou imaginação, o devir é real e escapa as representações.

\footnotetext{
${ }^{2}$ Spinoza (2009) no diz que os afetos ocorrem das afecções de um corpo, ou seja, do encontro de um corpo com o outro. Assim, quando somos afetados por outros corpos a nossa potência de agir aumenta ou diminui. Corroborando com Spinoza, Machado (2009, p. 76) diz que "quando a potência de agir aumenta, sinto alegria, e quando a potência de agir diminui, sinto tristeza". Ao encontrarmos um corpo que combina, que se compõe com o nosso afeto de alegria, Spinoza chama isso de "bom encontro", mas, quando um afeto de tristeza diminui a nossa potência de agir, Spinoza considera que tivemos um "mau encontro". É nesse sentido, que o presente trabalho de pesquisa considera a importância dos "bons" encontros e composições para o fortalecimento do trabalho coletivo e das invenções curriculares.

${ }^{3}$ Optamos por trabalhar ao longo do texto com a palavra no feminino, ou seja, "professoras", por se constituírem maioria no campo docente da Educação Infantil e, especialmente, no contexto da instituição em que se desenvolve a nossa pesquisa de campo.
} 
Devir é, a partir das formas que se tem, do sujeito que se é, dos órgãos que se possui ou das funções que se preenche, extrair partículas, entre as quais instauramos relações de movimento e repouso, de velocidade e lentidão, as mais próximas daquilo que estamos em vias de devir, e através das quais devimos. É nesse sentido que o devir é o processo de desejo. (DELEUZE; GUATTARI, 2012, p. 67).

Portanto, devir-lobo não se trata de imitar o lobo, nem de se assemelhar ao animal, mas se trata de "dar às partes do nosso corpo relações de velocidade e lentidão" que nos façam devir lobo "num agenciamento original que não procede por semelhança ou por analogia" (DELEUZE; GUATTARI, 2012, p. 46).

Assim, nesse plano de composição, o grupo de professoras e crianças e o lobo não são a mesma coisa, mas são dois num só e mesmo sentido. Os lobos são intensidades, velocidades que nos atravessam. Isso não é uma analogia, nem uma imaginação, mas uma composição de velocidades e afectos onde professoras e crianças experimentam devires. Devires que os possibilitam viver intensamente as relações no cotidiano escolar como matilha de lobos, se movendo como um organismo vivo pela florestaescola ${ }^{4}$, encontrando sinais, rastros no currículo que os levem aos movimentos de invenção, de criação.

Entretanto, ao falarmos em matilhas não estamos nos referindo a ajuntamento de pessoas, pois viver em matilha não é necessariamente viver em quantidade numérica; seus elementos são partículas, "sua quantidade são intensidades, são diferenças de intensidade" (DELEUZE, GUATTARI, 2011, p. 60). As matilhas são composições em redes de afetos, afecções, linguagens e conhecimentos que em movimentos constantes e aventureiros comportam multiplicidades de desejos intensivos e pensamentos selvagens que viajam explorando territórios, resistem à domesticação e se proliferam por contágio, formando multiplicidades selvagens as quais os diagramas da normatização não conseguem aprisionar com facilidade.

No trabalho coletivo a multiplicidade é partilhada, ou podemos dizer, as singularidades são partilhadas, pois os elementos da multiplicidade são as singularidades (DELEUZE; GUATTARI; 2011). Essa multiplicidade partilhada faz emergir uma "inteligência coletiva" que Carvalho (2009) chama de potência de ação coletiva; e, essa potência só se torna efetiva por meio da interação, das relações. Assim, quando indivíduos e grupos interagem no cotidiano escolar, colocando-se em relação, ocorre à expansão da potência coletiva na/da escola capaz de produzir resistências e romper com as formas (PARAÍSO, 2015) enrijecidas do currículo.

Mas, o que entendemos por "trabalho coletivo"? Entendemos que não se refere ao agrupamento de pessoas que se esforçam para trabalhar de forma consensual, mas como forças em relação, como singularidades que se comunicam e se articulam, buscando constituir o "comum" na diferença. Esse comum nada tem a ver com consenso ou com homogeneização, mas como "proliferação de atividades criativas, relações ou formas associativas diferentes". (CARVALHO, 2009, p. 162). É construído na relação com o outro, na articulação de conversações e ações. Nesse sentido, a interação por meio dos encontros coletivos na escola potencializa a constituição desse comum plural.

Mas, por que resistir ao que é padrão no currículo? Porque o currículo não é somente o que vem prescrito legalmente em atos formais, mas "constitui-se de tudo aquilo que é vivido, sentido, praticado no âmbito escolar e que está colocado na forma de documentos escritos, conversações, sentimentos e ações concretas vividas/praticadas pelos praticantes do cotidiano" (CARVALHO, 2009, p. 179) e, portanto, é produzido em meio a agenciamentos coletivos de

\footnotetext{
${ }^{4}$ Nilda Alves nos ensinou essa forma de escrita unindo palavras para criar uma nova, ou seja, que não é nenhuma nem outra, mas uma terceira, formando novos sentidos num jogo de criação e invenção.
} 
enunciação, que "não corresponde nem a uma entidade individuada, nem a uma entidade social predeterminada" (GUATTARI; ROLNIK, 1996, p. 31).

Embora para muitas professoras o currículo se reduza apenas às proposições das secretarias de educação, não podemos limitá-lo, pois o mesmo está imbricado numa rede composta por forças em relação, onde as ações e as conversações atravessam diferentes esferas do contexto educativo (escola, família, comunidade escolar, órgãos gestores, sistema político-administrativo, etc.).

Essa é a concepção de currículo como redes de conversações e ações complexas (CARVALHO, 2009) que é também a nossa aposta, pois considera a potência coletiva, a força das relações, dos agenciamentos, dos encontros, das composições, onde o sujeito só existe em relação. Logo, não centralizamos e reduzimos o currículo apenas às prescrições de currículos oficiais, mas, também não negamos a importância destes. Contudo, visualizamos os currículos oficiais "como textos e não como ponto de partida para orientar as mudanças educativas" (CARVALHO, 2009, p. 184). O que se intenciona é desterritorializar os princípios, as normas desses currículos formais para que aconteça a aprendizagem não prevista, inesperada, aquela que acontece fora dos engessamentos, escapando ao controle, produzindo diferença.

Isso não significa dizer que temos a pretensão de refutar ou apontar o certo ou o errado em relação aos currículos atuais, de dizer se são verdadeiros ou falsos ou mesmo apresentar consenso sobre o que vem a ser o "currículo ideal", mas intencionamos pensá-los de outra maneira, produzi-los de outras/novas formas.

\section{Por uma educação com as matilhas: a potência do trabalho coletivo na produção de outros sentidos para o currículo}

Os "bons" encontros estabelecidos em nosso movimento de pesquisa moveram o nosso pensamento em relação às diferentes práticas discursivas no campo da educação, uma multiplicidade de verdades e saberes produzido que constituem imagens de currículo, criança e infância. Imagens que deslocam e movimentam o nosso pensamento na tentativa de compreender práticas educativas com crianças e políticas de currículo que se estabelecem na educação infantil.

Deleuze e Guattari (2011) ao nos apresentar, a partir de Elias Canetti, os conceitos de massa e matilha contribui com a nossa intenção de problematizarmos essas imagens e, portanto, dispara o nosso pensamento em direção à educação que se desenvolve no cotidiano escolar. Assim, observamos a coexistência, no contexto da educação infantil, de uma educação pensada para as massas e uma educação produzida com as matilhas.

Para os filósofos, massa e matilha são "dois tipos de multiplicidade que às vezes se opõe e às vezes se penetram" (DELEUZE; GUATTARI, 2011, p. 60) e possuem características distintas. As multiplicidades de massa possuem caracteres mais identitários, totalitários e homogêneos, como nos aponta Deleuze; e Guattari (2011, p. 60): "Entre os caracteres de massa, no sentido de Canetti, precisa-se notar a grande quantidade, a divisibilidade e a igualdade dos membros, a concentração, a sociabilidade do conjunto, a unicidade da direção hierárquica, a organização de territorialização, a emissão de signos".

No contexto da educação infantil, as práticas discursivas que produzem uma educação para as massas caminham na direção do uno e conformam subjetividades de crianças e professoras de acordo com modos e modelos de agir hegemônicos.

Foi o que percebemos na reação de uma criança, no momento em que brincava no parquinho da escola. Ao receber o pedido "inusitado" da colega para fazer o papel de policial na brincadeira, o menino rapidamente resistiu afirmando: "Não, você não pode, você é menina, só menino que pode". A menina, contrariada, insistiu dizendo já ter visto uma "policial mulher", o que não convenceu o menino, que veio rapidamente na nossa direção: “Tia, não existe policia 
mulher, né?" A pergunta ressoou mais como a força de uma afirmação do que como um questionamento. Na intenção de não apresentar uma resposta pronta e possibilitar o movimentar do pensamento com a criança, respondemos com outra pergunta: "Por que não? Você acha que não existe?" E o menino nos surpreendeu com sua resposta rápida e cheia de certeza: "Não. Porque o homem é mais forte! Meu pai falou que é serviço de homem".

Silva (2019, p. 285) nos diz que "[...] estamos cercados de imagens por todos os lados e de experiências imagéticas que possibilitam encontros com diferentes linguagens e afecções, produtoras de pensamento e de conhecimento". Esclarece-nos que existem imagens como palavras de ordem, centradas na identidade, que informa, conforma e remete a diferença ao erro. É nessa lógica que se fundamenta o argumento da criança. Com um pensamento representativo de quem deveria ser policial, formou uma imagem centrada na identidade. Imagem que conduz a homogeneidade das massas.

Percebe-se, com essa situação, a urgente necessidade de discutirmos a diferença como prática da educação. Nesse caso, a pergunta de Simonini (2015, p. 11) nos parece bastante conveniente: “[...] qual o local do professor na educação: um sacerdote da normalidade ou um problematizador de diferentes processos relacionais nos contextos de aprendizagem?".

Defendendo a diferença como prática da educação, acreditamos que o papel do professor deve ser o de problematizar verdades cristalizadas, acompanhando devires que nos atravessam, permitindo nos permeabilizar a outros mundos de referência e a outros modos de existir (SIMONINI, 2015). Foi o que aconteceu ao prolongarmos o diálogo com as crianças, onde tivemos a oportunidade de problematizar verdades que traziam consigo sobre questões de gênero.

Nessa lógica da padronização imagens de criança e infância também são forjadas na perspectiva de uma educação para as massas. Amparadas e potencializadas em concepções lineares e cronológicas de várias teorias de desenvolvimento infantil afirmam a temporalidade dos estágios e das fases de desenvolvimento em detrimento das relações, dos agenciamentos no desenvolvimento da criança.

Essas imagens revelam uma concepção de criança como ser incapaz e a infância associada à imaturidade, tendo no adulto seu ponto de chegada, o seu referencial, assim como percebemos no argumento da professora ao falarmos da nossa proposta em trabalhar com as crianças a ideia de coletividade: "E as crianças vão saber alguma coisa de coletivo? Sei não, heim! Elas são muito pequenas ainda. Essa fase é muito egocêntrica, acho meio dificil falarem sobre isso, mas, tenta né!"

Tal modo de conceber as crianças e as infâncias afeta consideravelmente o currículo de maneira que, no seu sentido vertical, condicione e organize as práticas de professores em função do que "falta" na criança em relação ao adulto. Traz para o cotidiano das escolas um currículo préformatado, engessado, que não leva em conta a diferença de cada um. “- Viu como eles já estão escrevendo bem? Minha vontade era de dar mais de uma atividade por dia, mas eles não aguentam, começam a reclamar, é uma preguiça só! Mas, eu acho que a maioria vai sair lendo e escrevendo, dá tempo ainda”. (Redes de conversações- Diário de campo da Pesquisadora-2019).

Repetições de exercício, prioridade para atividades escritas, listas intermináveis de palavras desconexas, rotinas fatigantes, mesmice... E a maioria, que vai sair lendo e escrevendo? Ela sim tem importância numa educação para as massas. Maioria passiva, subordinada, conformada, idealizada.

Segundo Paraíso (2015, p. 52) "um currículo quando se formata demais, espalha tristeza, desânimo ou indiferença" e "o aprender se distancia". É dentro dessa lógica que a produção do fracasso consequentemente ganha força e se torna evidente nos clichês enunciados: "criança muito pequena, não sabe nada ainda", "criança preguiçosa", "pais que não colaboram", "esse menino não quer nada com nada", "essa professora não faz nada". Formas excludentes que "hierarquizam, explicam comportamentos, justificam resultados nas avaliações" (PARAÍSO, 
2015, p. 52) e busca culpabilizar crianças, famílias e professores pelo fracasso. É nessa lógica que operam os sistemas de avaliação, adotando um modelo igualitário para todos os sujeitos, acreditando que todos aprendem de igual modo no mesmo espaço-tempo.

Mas, é só esse tipo de educação que se presencia no cotidiano das escolas?

NÃO. Não mesmo. A vida sempre escapa, não se deixa aprisionar, não se deixa domesticar. Carvalho, Silva e Delboni (2018, p. 808) nos afirmam que "em meio às tentativas de modelização e padronização, há possibilidades de rompermos com os mecanismos de aprisionamento". Desse modo, ao mesmo tempo em que presenciamos uma educação para as massas, também presenciamos uma educação com as matilhas no cotidiano escolar.

Uma educação com as matilhas pensa o currículo "com" e não "para", considerando a potência da (com)posição na complexa dinâmica do cotidiano escolar. Os movimentos curriculares são ampliados entre multiplicidades, favorecendo as trocas, o compartilhar de ideias, o fervilhar da criatividade e das invenções.

Embora haja diferença entre esses dois tipos de educação, não quereremos dizer que ambas estão polarizadas, isto é, ora acontece de uma forma, ora acontece de outra, seguindo um pensamento dualista. Mas, podemos dizer que elas se desenvolvem no cotidiano escolar de forma coengendrada, como nos indica Deleuze e Guattari (2011, p. 62) ao falar do entrecruzamento das multiplicidades, "existem unicamente multiplicidades de multiplicidades que formam um mesmo agenciamento, que se exercem no mesmo agenciamento: as matilhas nas massas e inversamente".

Diferente de uma educação para as massas que prioriza a identidade, o consenso e a homogeneidade, uma educação com as matilhas está baseada na diferença, naquilo que escapa, nas linhas de fuga, nos movimentos de desterritorialização. Em relação aos caracteres de matilha, Deleuze e Guattari (2011, p. 60) destacam:

[...] a exigüidade ou a restrição do número, a dispersão, as distâncias variáveis indecomponíveis, as metamorfoses qualitativas, as desigualdades como restos ou ultrapassagens, a impossibilidade de uma totalização ou de uma hierarquização fixas, a variedade browniana das direções, as linhas de desterritorialização, a projeção de partículas.

Nesse sentido, os currículos pensados numa educação com as matilhas, não possuem uma direção una, não são lineares, mas, operam em várias direções, se movimentam por caminhos pseudo-aleatórios como num movimento "browniano", se recusando a operar por fixidez. O diálogo com uma professora de grupo $\mathrm{V}$ mostra claramente o desejo de resistir a esse currículo padronizado:

- Eu resolvi mudar. Ano que vem não vou mais planejar projetos e atividades com base na ordem alfabética. É um desespero no final. A gente percebe que não vai dar tempo de trabalhar todas as letras e dá uma sensação de frustração, como se a gente não tivesse dado conta do recado. As crianças já demonstram cansaço e a gente também. Fica chato. E, se parar pra refletir, vai ver que a gente já trabalhou tanta coisa durante o ano, um monte de outros aprendizados. Ai... chega! (Fala de professora de grupo V- Diário de campo da pesquisadora-2020).

Ao desatrelar-se da linearidade, os currículos pensados numa educação com as matilhas fogem ao plano arborescente, onde as árvores crescem para o alto numa única direção. Eles operam como os rizomas (DELEUZE;GUATTARI, 2011) cujas hastes subterrâneas se espalham em qualquer direção e podem ser conectadas em qualquer ponto, produzindo novas 
possibilidades. Considera saberes dos professores, das crianças, dos pais e de todos os integrantes do processo educativo para compor sua proposta pedagógica.

E assim se destaca outra característica importante de uma educação com as matilhas: a coletividade. Esse tipo de educação se desenvolve na força dos agenciamentos, nas relações entre professores, crianças e todo o contexto social. Cada ideia, cada ação deve envolver o coletivo, mesmo que se inicie no individual, como nos inspira Gallo ao afirmar que "todo o ato singular se coletiviza e todo o ato coletivo se singulariza" $(2017$, p. 69).

$\mathrm{Na}$ matilha, professoras e crianças organizam o trabalho coletivo como lobos-caçadores, onde "cada um efetua sua própria ação ao mesmo tempo em que participa do bando" (DELEUZE; GUATTARI, 2011, p. 61). Essa organização própria faz das composições em matilha potência do trabalho coletivo para romper padrões e trazer mais vida ao cotidiano da educação infantil. Organização que se mostra potente inclusive entre as crianças.

Numa tarde, ao acompanhar o movimento das crianças, um menino nos fez um pedido: Tia, você deixa a gente brincar com os brinquedos no chão? Através das explicações de outras crianças, percebemos que havia um combinado feito pela professora de que só poderiam brincar na sala de aula se permanecem sentados com os brinquedos sobre a mesa. Na intenção de atender o pedido das crianças feito com tantas súplicas, propomos o acordo de que poderiam brincar, desde que guardassem todos os brinquedos quando a professora chegasse. Acordo aceito. Euforia total. De repente, nos deparamos com um diálogo singular entre duas crianças:

(criança 1) -Óh, você fica na porta e eu brinco aqui com o carrinho, depois você vem brincar um pouquinho também, tá bom?

(criança 2) -Ah não! Eu quero brincar também.

(criança 1) -Espera, você vai brincar. Mas, tem que vigiar a tia chegar, pra gente guardar os brinquedos logo. Se não ela vai brigar com a gente. Eu brinco um pouquinho e depois é você, tá bom? Aí depois eu vigio também (Diálogo entre crianças. Diário de campo da pesquisadora-2019).

Notamos que as crianças organizaram uma maneira de brincar de forma livre com os brinquedos no chão, mas não queriam ser "pegas" de surpresa pela professora que iria retornar em breve. Afinal, estavam transgredindo um combinado. A negociação e o modo como as crianças constituiram o comum na diferença foi surpreendente, apesar de não terem levado a sério até o final, pois quando a professora chegou, eles já estavam brincando todos juntos ao mesmo tempo e havia brinquedos espalhados por toda a sala. Afinal, criança é puro movimento! Elas não precisam se espelhar no adulto como referencial, elas vivem em devires, devir-criança.

Assim, com a força da invenção e experimentação presentes no devir-criança, percebemos que elas conseguem sim trabalharem no coletivo, ao contrário do que disse uma professora anteriormente. Elas têm seus modos próprios de matilha e, portanto, têm muito a nos dizer sobre trabalho coletivo.

As professoras também se destacam como "lobos-caçadores" ao se organizarem na perspectiva de uma educação com as matilhas. Em uma das redes de conversações no início do ano letivo cartografamos o modo como o encontro de professoras em matilha culminou num movimento de resistência ao instituído.

A primeira reunião do ano trouxe o desafio de uma nova proposta de trabalho. A diretora comunicou sobre o novo projeto enviado pela secretaria de educação, o projeto FeliS ${ }^{5}$, que orientava

\footnotetext{
${ }^{5}$ Segundo publicação no site da Prefeitura Municipal da Serra “a Festa Literária da Serra (FeliS) visa fomentar e divulgar a produção literária, científica, artística e cultural, que é potencializada pelo trabalho pedagógico" e, também, "valorizar a literatura em seus aspectos histórico-culturais no âmbito escolar, promovendo diálogo com diferentes componentes curriculares". Ainda, segundo a proposta, "alunos e equipe escolar vão produzir projetos pedagógicos a partir de obras
} 
os professores a escolherem e trabalharem com as crianças uma determinada obra de literatura infantil de autores capixabas, com o objetivo de incentivar a leitura e valorizar a literatura infantil.

Entretanto, as professoras logo demonstraram insatisfação com a orientação da proposta em determinar a escolha de apenas uma obra de literatura infantil para o trabalho com as crianças. Consideraram ser essa uma imposição, uma forma de engessar o trabalho que poderia ser bem mais rico se houvesse liberdade para escolher outras obras, de acordo com as necessidades que iriam surgir no decorrer do ano. Rapidamente questionaram a diretora, que confirmou dizendo que essa orientação foi repassada em reunião aos diretores pela própria secretaria de educação.

Nesse aspecto, concordamos com Carvalho (2009, p. 196) que "é necessário evitar a mutilação da espontaneidade, da alegria de aprender, do prazer de criar nas salas de aula das escolas [...], devemos explorar o currículo como um 'acontecimento' vivido nele mesmo".

Então, após ouvir e dialogar com as professoras, ficou acordado que a diretora levaria os questionamentos e a proposta de um trabalho mais livre para a próxima reunião de diretores. A matilha se posicionou resistindo a domesticação da norma, e através da articulação de conversações e ações, buscou outro sentido para o currículo que tentava aprisionar a vida. Interação que gera mudanças, pois "o currículo muda à medida que nos envolvemos com ele, refletimos sobre ele, consideramos sua complexidade tecida em redes de conversações e agimos em direção a sua realização, buscando nos afetos e afecções a potência inventiva de um currículo não burocratizado e normalizado" (CARVALHO, 2009, p. 196).

Ao retornarmos à escola na semana posterior, em movimento de pesquisa, descobrimos que as observações das professoras, bem como de outras instituições do município, foram consideradas pela Secretaria de Educação e a proposta foi alterada, concedendo liberdade aos professores para escolher mais de uma obra literária. Também, ficamos sabendo que a Secretaria de educação havia reforçado a orientação para que as escolas dessem preferência a autores capixaba na escolha dos livros, de modo a valorizar e fazer conhecida a literatura infantil do Espírito Santo. Nesse quesito não houve resistência por parte dos professores que, aprovaram a ideia, embora tenham admitido à necessidade de terem que pesquisar mais sobre esses autores até então "desconhecidos" por alguns, ou seja, viram nessa situação oportunidade para ampliarem seus conhecimentos.

Foi interessante notar o modo como às professoras utilizaram a conversação para partilharem experiências e constituírem um comum, mantendo as diferenças. Como já dissemos anteriormente, comum entendido como comunicação de singularidades, proliferação de atividades criativas, não como consenso. Comum que é constituído em meio a negociações, conflitos, divergências e convergências de ideias.

Assim operam as composições em matilhas, seguindo as linhas de desterritorialização, pois, como afirma Deleuze e Guattari (2012, p. 24) "a origem das matilhas é totalmente outra que a das famílias e dos Estads e ela não para de trabalhá-las por baixo, de perturbálas de fora, com outras formas de conteúdo, outras formas de expressão". As professoras receberam uma proposta fechada, pronta, vertical, arborescente, mas como matilha, trabalharam-na por baixo, perturbaram de fora, apresentaram outras formas de trabalho, expressaram afetos que movimentaram novos processos de subjetivação e novas invenções curriculares. Nesse processo de contágio outras escolas se uniram na reunião de diretores e expressaram o desejo por mudança na proposta do projeto.

da literatura capixaba e nacional durante o ano. A Sedu (Secretaria de educação da Serra) também vai promover encontros de estudantes e professores com autores da literatura serrana e capixaba, realizar mostra literária e assessoramento pedagógico nas escolas [...], realizar formações de professores, concurso literário, exposição de projetos artísticos e muito mais". (FONTE: http://www.serra.es.gov.br:8080/site/publicacao/festa-literaria-com-duracao-de-umano-e-criada-para-alunos-e-professores-da-serra. Acesso em 10 de abr. 2020). 


\title{
2. Algumas considerações finais...
}

\author{
Não se pode domar um lobo selvagem... Nem tentar \\ aprisionar o espírito de liberdade do lobo... Não se \\ pode calar o uivo do lobo em noites de luar... Pois, se \\ tirarem-lhe a liberdade, o condenam a morte, mas o \\ espírito Lupino continuará a existir. \\ Roseane Rodrigues
}

Como domar a matilha de professoras e crianças na força do trabalho coletivo? Lobos não podem ser domados. A vida sempre escapa. A matilha sobrevive.

Assim, por meio de "bons" encontros, os protagonistas do processo educativo ao se colocarem abertos às relações potencializam a constituição do "comum", fortalecendo o trabalho coletivo e os movimentos inventivos curriculares.

\section{Referências}

CARVALHO, J. M. O cotidiano escolar como comunidade de afetos. Petrópolis: DP et Alii, 2009.

CARVAlHO, J. M.; SILVA, S. K.; DELBONI, T. M. Z. G. F. Currículos como corpos coletivos. Currículo sem Fronteiras, v. 18, n. 3, p. 801-818, set./dez. 2018.

DELEUZE, G.; GUATTARI, F. Mil platôs: capitalismo e esquizofrenia, vol. 1. Trad. Ana Lúcia Oliveira, Aurélio G. Neto e Celia P. Costa. 2. ed. São Paulo: Editora. 34, 2011.

DELEUZE, G.; GUATTARI, F. Mil platôs: capitalismo e esquizofrenia, vol. 4. São Paulo: Ed. 34, 2012.

GALLO, S. Deleuze e a educação. 3. ed. Belo Horizonte: Autêntica, 2017.

GUATTARI, F.; ROLNIK, S. Micropolítica: cartografias do desejo. Petrópolis: Vozes, 1996.

MACHADO, R. Deleuze, a arte e a filosofia. Rio de Janeiro: Jorge Zahar Ed., 2009.

PARAÍSO, M. A. Um currículo entre formas e forças. Educação, v. 38, n. 1, p. 49-58, 2015. Disponível em: http://revistaseletronicas.pucrs.br/ojs/index.php/faced/article/view/18443. Acesso em: 01 abr. 2020.

SILVA, S. K. As imagens-cinematográficas como força que impulsiona o devir-pensamento no cotidiano escolar. Revista Teias, v. 20, n. 59, p. 283-300, out./dez. 2019.

SIMONINI, E. Currículo e devir. In: FERRAÇO, C. E.; RANGEL, I. S.; CARVALHO, J. M.; NUNES, K. R. (Org.). Diferentes perspectivas de currículo na atualidade. Rio de Janeiro: DPetAlii, 2015. p. 63-78.

SPINOZA, B. Ética. Trad. Tomaz Tadeu. Belo Horizonte: Autêntica, 2009. 